\title{
How much biodiversity loss is too much?
}

Article

Accepted Version

Oliver, T. H. (2016) How much biodiversity loss is too much? Science, 353 (6296). pp. 220-221. ISSN 0036-8075 doi: https://doi.org/10.1126/science.aag1712 Available at https://centaur.reading.ac.uk/66325/

It is advisable to refer to the publisher's version if you intend to cite from the work. See Guidance on citing.

To link to this article DOI: http://dx.doi.org/10.1126/science.aag1712

Publisher: American Association for the Advancement of Science

All outputs in CentAUR are protected by Intellectual Property Rights law, including copyright law. Copyright and IPR is retained by the creators or other copyright holders. Terms and conditions for use of this material are defined in the End User Agreement.

\section{www.reading.ac.uk/centaur}

\section{CentAUR}

Central Archive at the University of Reading

Reading's research outputs online 


\section{Biodiversity loss- how much is too much?}

\section{Tom H. Oliver}

University of Reading, School of Biological Sciences, Whiteknights, Harborne Building, RG66AS t.oliver@reading.ac.uk ; Tel: 01183787016

How much of something do we need to keep people safe and well? It's a question that is frequently asked by those working in risk management. Across diverse sectors, from flood protection to healthcare, practitioners assess risk as the product of the impact of a given event and the probability of its occurrence. There can be substantial uncertainty around these estimates, but this cannot hold back decisions indefinitely. Politicians must ultimately commit to spending on flood defences, or how many flu vaccines to stockpile, because the costs of inaction to society can be substantial. Biodiversity loss is similarly a critical issue. A paper in this issue by Newbold et al. (1) quantifies global biodiversity losses, whilst economic analyses suggest that the total global value of ecosystem services, many of which are underpinned by this biodiversity, are in the realm of tens of trillions of dollars (2). However, there is currently a lack of co-ordinated action to halt biodiversity declines, despite repeated setting of international targets (including the 2011-2020 Aichi Targets adopted by the Convention on Biological Diversity; 3).

So why the lack of adequate action to reverse biodiversity declines? We know, broadly, the type of actions that are needed. They include well-researched habitat restoration methods, as well as limiting human-derived pressures such as habitat loss, pollution and invasive species. The opportunity costs of these actions, however, in combination with the high levels of uncertainty around biodiversity change, appear to be hampering commitment to ameliorative actions. This uncertainty has multiple components: we must ascertain, firstly, the current extent of biodiversity loss, and, secondly, the impacts of these losses on people's health and wellbeing. The Newbold et al. study makes a significant advance in tackling these issues. Their analysis is the most comprehensive quantification of global biodiversity change to date, considering over 1.8 million records of abundance from 39,123 species across 18,659 sites. They find that the average local abundance of species present has fallen to around $85 \%$ of its original value in the absence of human land use (i.e. 85\% 'biodiversity intactness'; 4), with wide variation in biodiversity losses across biomes. The authors then go further to relate these losses to a planetary 'safe limit' of $90 \%$ biodiversity intactness as proposed in a recent study (5). The hypothesis is that below the 'safe limit', the wide range of services provided by 
biodiversity that underpin human well-being (e.g. pollination of crops, decomposition of waste, regulation of the global carbon cycle, and cultural services that are central to emotional and spiritual health) are critically threatened (5). Crucially, Newbold et al. find that around $58 \%$ of the world's land surface, and 9 out of 14 terrestrial biomes, have fallen below this safe threshold.

One might ask, if such a large proportion of land has exceeded the planetary boundary for biodiversity loss, why have we not already noticed more widespread negative impacts on humans? It is clear that biodiversity loss can lead to quite dramatic and rapid impacts on ecosystem services. For example, invasion by the spiny water flea Bythotrephes longimanus in Lake Mendota in Madison, Wisconsin, USA, caused declines in key algal-grazing zooplankton species and consequent reductions in water quality, which will cost $\$ 86$ million to $\$ 163$ million to restore. (6). However, in many other cases there may be delayed effects, with ecosystem services only lost after further perturbation (7). This is akin to cumulative structural damage occurring to a bridge, only leading to sudden collapse after an extreme storm. Recovery from such catastrophic 'tipping points' can be very costly (i.e. the complete replacement cost far exceeding the ongoing repair costs), but unlike other sectors, the environment may be unique in that the extinction of species is effectively irreversible.

The existence of tipping points in nature has been hotly contested within the ecological literature; there is ongoing debate over whether thresholds for tipping points are planetary or regional (8; and they could be both or neither). It is also unclear whether non-native species should be included the accounting of biodiversity change; it depends on their capacity to replace the roles played by disappearing native species. Reflecting this uncertainty, Newbold et al. conducted sensitivity analyses. One analysis included non-native species as functioning biodiversity, and this made some difference to the results; only $48 \%$ of the global land area was below the safe limit. An even more marked difference in the results occurred, however, when the threshold for safe levels of biodiversity intactness was varied. For example, if the safe limit threshold is $80 \%$ rather than $90 \%$, then the area falling below safe limits is closer to one third of the global land area (and even lower if non-native species are included in calculations). Clearly, it is crucial to reduce uncertainty around the existence and position of tipping point thresholds. Further research could also investigate whether 'safe limits' are context dependent. For example, the longer the time window of interest, the higher are the chances of a large environmental perturbation, and the greater the level of system resilience 
needed. Safe limits may also vary between the different ecosystem services provided by species (Fig. 1).

The Newbold et al. paper marks a significant step in our ability to quantify biodiversity loss. There is still further work needed; for example, local biodiversity changes were estimated by statistical models downscaling land cover changes and inferring the proportion of non-native species, so further data collection, especially in data sparse countries, is essential to reduce uncertainty in these models. However, the most substantial and pressing knowledge gap now is to move from documenting biodiversity changes to understanding the impacts of these on people's health and wellbeing. Such research is underway (e.g. the rapidly moving fields of 'biodiversity-ecosystem function' and ecosystem service research), but a more quantitative assessment of risk is urgently needed to prompt commitment to potentially costly ameliorative actions. For example, the UK government only committed to serious action in combatting climate change after risks were quantified through meticulous science combined with economic analysis of impacts (9). It may be impossible, however, to reduce uncertainty to levels achieved in other sectors that deal with risk management. The challenge, therefore, is to find new approaches to decision-making in the face of this uncertainty. These decisions should be viewed within the context of the environment-governance- justice nexus, considering the fair distribution of risks across demographic groups, as well as intergenerational equity. Furthermore, in some locations, some level of natural resource exploitation, with inevitable biodiversity loss, may be essential to raise the living standards of the world's poorest to achieve basic human rights (10). Taking decisions in the face of such uncertainty is not easy. It is a tricky problem to say how much biodiversity loss is too much. However, it should be remembered that inaction is an implicit commitment to an endpoint with substantial costs $(2,11)$. 
Intact biodiversity

Safe limit for ecosystem service delivery under longer time window

i Safe limit under shorter time window

Biodiversity losses

Timber producing species

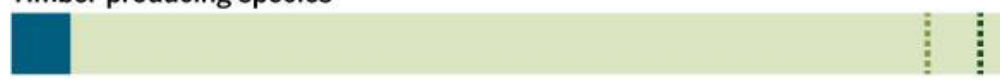

Carbon sequestering species

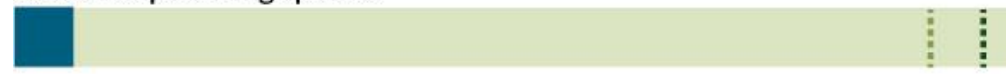

Decomposers

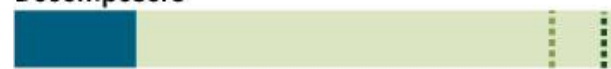

Pollinators

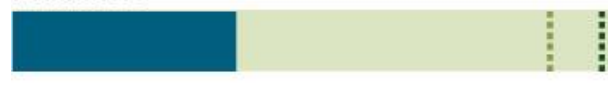

Pest controlling species

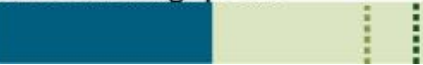

Fig. 1, Boundaries for biodiversity loss on services. The extent of biodiversity losses varies between groups of species that provide different services (12), as may the safe limits beyond which biodiversity loss will have substantial effects on human well-being. The figure only shows a subset of services provided by species. The extent of biodiversity loss and the safe limits depicted are purely hypothetical

\section{Acknowledgements}

Thanks to M.S. Heard, R.W. Jackson, M.D. Pagel, R.M. Sibly and P.J. Stoett for discussion and comments. 


\section{References}

1. T. Newbold et al., Science (This issue), (2016).

2. R. Costanza et al., Global Environmental Change 26, 152-158 (2014).

3. D. P. Tittensor et al., Science 346, 241-244 (2014).

4. R. J. Scholes, R. Biggs, Nature 434, 45-49 (2005).

5. W. Steffen et al., Science 347, 736 (2015).

6. J. R. Walsh, S. R. Carpenter, M. J. Vander Zanden, PNAS 113, 4081-4085 (2016).

7. T. H. Oliver et al., Trends Ecol. Evol. 30, 673-684 (2015).

8. T. M. Lenton, H. T. P. Williams, Trends Ecol. Evol. 28, 380-382 (2013).

9. N. Stern, Stern review on the economics of climate change. (Stern Review on the Economics of Climate Change, UK Treasury, 2006).

10. K. Raworth, Oxfam Policy and Practice: Climate Change and Resilience 8, 1-26 (2012).

11. S. Díaz, J. Fargione, F. S. Chapin, III, D. Tilman, PLoS Biol 4, e277 (2006).

12. T. H. Oliver et al., Nature Communications 6, (2015). 